\title{
The Impact of Gamified Recruitment on Team Effectiveness in the Telecom Sector of Pakistan
}

\author{
Sanaullah Abro ${ }^{1,}$, Nazar Hussain ${ }^{1}$, Shumaila ${ }^{2}$, Shoukat Ali Mahar ${ }^{1}$, Mujeeb Ur Rehman ${ }^{3}$, Muhammad \\ Auchar Zardari ${ }^{1}$, Jawaid Shabbir ${ }^{4}$ \\ ${ }^{1}$ Department of Public Administration, SALU Khairpur Mirs, Pakistan. \\ ${ }^{2}$ School of Management, Wuhan University of Technology, China. \\ ${ }^{3}$ Department of Media and Communication Studies, SALU, Khairpur Mirs, Pakistan. \\ ${ }^{4}$ Department of Computer Engineering, Sir Syed University of Engineering \& Technology, Karachi, Pakistan. \\ ${ }^{*}$ Corresponding author: sanaullahniaz@gmail.com
}

\section{Abstract}

This study has been designed to evaluate the impact of gamified recruitment on team effectiveness in the telecom sector of Pakistan. The sample of 120 respondents was designed to collect the data. This includes 30 respondents each from 4 telecom sector organizations of Pakistan. 110 responses returned complete feedback which gave the response rate of $91.66 \%$. The results reveal that there is a positive impact of the gamified recruitment on team effectiveness at the telecom sector of Pakistan. As the model fitness is highly appreciated which is 0.850 at alpha is equals to 0.000 while beta is $92.3 \%$. Similarly, the persuasive, economic, and informative value of gamified recruitment has been tested on virtual teams' dimension of team effectiveness of the telecom sector of Pakistan. The model fitness was found $73 \%$ and the values found to be significant and influencing to accept the hypothesis. Moreover, similar results have also been identified after testing the persuasive, economic, and informative value of the gamified recruitment to the physical and project teams' effectiveness at the telecom sector of Pakistan.

Keywords-Oedometer Gamified Recruitment, Team Effectiveness, Persuasive Value, Economic Value, Informative value, Virtual Team, Physical Team, Project Team, Telecom Sector, Pakistan

\section{Research Background}

W ITH the rapid and dynamic change in the working environment, organizations are nowadays facing even harder competition [1][2]. Digitalization and globalization have set management to think out of the box in order to get sustainability and profitability within the markets [2]. The trends have now further changed with the inclusion of unexpected variables like a pandemic in the shape of COVID-19 which the world is still facing and none of the organization can yet predict the future of the stability of the working environment [3]. Considering these facts, this study has been designed to study the latest trends related to the working environment to recommend better opportunities which organizations can cope in time to meet the needs of the customers and have proper

ISSN: 2523-0379 (Online), ISSN: 1605-8607 (Print)

DOI: 10.52584/QRJ.1802.16

This is an open access article published by Quaid-e-Awam University of Engineering Science $\&$ Technology, Nawabshah, Pakistan under CC BY 4.0 International License. sustainability and growth in the global and domestic markets [1][2].

Researchers have suggested that integrating the gamification in the working environment can enhance employees participation at the workplace [2], employees' engagement[4], and employees' loyalty with the organization. There are more than $70 \%$ of the global fortune-500 companies who adopt at least one of the gamification practices at workplace and nearly $40 \%$ of the fortune-1000 companies adopt gamification practices at their workplace [5]. This makes gamification one of the most important and prominent factors of the current trends and the need of today's organizations [5][6].

Gamification is defined as management's practices of using serious games in a non-gaming context at the workplace [7]. Serious games in the non-gaming context are created with the help of modern digital technologies and the fundamentals of the entertainment and brainstorming exercises [2][7]. Using the 
gamification, organizations convey some work-related messages and want to encourage employees to gain motivation by competing for the challenging tasks to reach both personal and organizational-specific objectives [8]. Some of the global fortune-1000 companies including Cisco, IKEA, Deloitte, etc. are using gamification as their HR processes including recruitment process, training and development process, assessment process, and also in the evaluation process of their HR functions [9][10]. In Pakistan, the gamification process is only implemented in the banking and telecom sector. This is now considered to be the part of the recruitment process [10][11]. Therefore, despite an increase in the adaptation of gamification practices globally, it is yet lacking in the human resource management processes particularly when it comes to the markets of Pakistan [10][12].

The objective of this study is to investigate the impact of gamified recruitment on team effectiveness in the telecom sector of Pakistan. The reason behind studying telecom sector is because this sector is already using gamified recruitment in their selection and recruitment process. Therefore, employees of this sector in Pakistan are much familiar with the system and they opine that the system would be much significant, relevant, and applicable.

\subsection{Research Objectives}

The main purpose of this study is to evaluate the impact of the gamified recruitment on Team effectiveness at the telecom sector of Pakistan The sub-objectives of the study are stated as follows.

1) To evaluate the impact of persuasive value (by executing gamified recruitment model) on virtual, physical and project teams at telecom sector of Pakistan

2) To evaluate the impact of economic value (by executing gamified recruitment model) on virtual, physical and project teams at telecom sector of Pakistan

3) To evaluate the impact of informative value (by executing gamified recruitment model) on virtual, physical and project teams at telecom sector of Pakistan

\section{Literature Review}

This study has been designed to collect and study theoretical and empirical evidence of the link between gamified recruitment on team effectiveness at the telecom sector of Pakistan. gamified recruitment is an application of game designed elements based on the serious games related to the defined objectives to be achieved which is used to recruit the best possible pool of the required workforce [8][9].

The gamified recruitment has been used as a tool for the performance management while using the modern digital technology to have a best possible recruiting pool of the candidates before going for the selection process [8]. These work-related serious games are developed to provide a cost-effective organizational orientation helps to enhance the intrinsic motivation of the individuals/prospects [10].

Fetzer et. al. [1] have identified gamified recruitment as an element of the job predictor for the incumbents at organizational setup. Gamified recruitment helps employers to attract the best possible pool of the candidates to get the best out of that pool [4]. Therefore, researchers opine that having the 'best employees' will lead to the team effectiveness and high profitability [2][6][13].

Three sub-variables have been taken as a dimension of each gamified recruitment and team effectiveness which is also supported by the Signaling theory [14]. The three dimensions of gamified recruitment include persuasive value, economic value, and informative value. According to the Signaling theory, in order to improve the recruitment process, it is important for employers to link it with the intrinsic motivation of the incumbents [14]. Gamified recruitment provides persuasive, economic, and informative value to both applicants as well as organization at the same time [15]. Moreover, these values help an employee to increase their intrinsic motivation, leading to better job performance and team effectiveness [6][15].

Similar to gamified recruitment, there are three dimensions of the team effectiveness which are undertaken in this study as components of the team effectiveness [3]. These components include the virtual team, physical teams, and project team. These are also three of the most popular types of teams in a workplace [3][16]. In this study, the impact of the dimensions of the gamified recruitment will also be measured to find their impact on all three popular types of the teams which include virtual team, physical team, and project team.

The previous studies have identified a positive link of the gamified recruitment with learning attitudes [17], efficiency and effectiveness of the individuals[18] and teams[4]. Along with that, the serious workrelated gamification has also found to have some positive impact on an educational setup, in particular, students. It has been identified that gamification has a positive link with the students' motivation [12], student's engagement[15], and student's performance[19]. This makes it a more significant and attractive factor 
for the working organizations to adopt and execute the practices at the working environment as well [15][19].

It is evident from the relevant literature that teamwork helps organizations to increase trust and accountability within the members of a team[3]. The teamwork has been identified to influence the gamified recruitment because it enhances the effectiveness and provides a valuable addition in terms of better employment[20], shared knowledge, and better skills of the employees working in a team [21]. Therefore, the literature supports the elements of the gamified recruitment which has a positive link with the physical, virtual, and project teams' effectiveness at a workplace $[5][6][20][21]$.

\section{Research Model}

Our research model is depicted in Figure 1.

\begin{tabular}{ll}
\multicolumn{1}{l}{ Independent Variable } & $\underline{\text { Dependent Variable }}$ \\
\begin{tabular}{|l|l|}
\hline Gamified recruitment \\
- persuasive value \\
- economic value \\
- informative value
\end{tabular} & $\begin{array}{l}\text { Team Effectiveness } \\
\text { - Virtual team } \\
\text { - Physical team } \\
\text { - Project Team }\end{array}$ \\
\hline
\end{tabular}

Fig. 1: Research Model

The research hypothesis are as follows.

- H1: There is a positive impact of the gamified recruitment on team effectiveness in the telecom sector of Pakistan

- H2: There is a positive impact of persuasive value (by executing gamified recruitment model) on virtual, physical and project teams in telecom sector of Pakistan d recruitment model) on project team at the telecom sector of Pakistan

- H3: There is a positive impact of economic value (by executing gamified recruitment model) on the virtual, physical and project teams at telecom sector of Pakistan

- H4: There is a positive impact of informative value (by executing gamified recruitment model) on the virtual, physical and project teams at telecom sector of Pakistan

\section{Research Methodology}

This study has been designed to measure the impact of gamified recruitment on team effectiveness at the telecom sector of Pakistan. The study is aimed at testing the nature (type) of the study which has been adopted to test the hypothesis in [22]. In this case study, the research design is set to be a cross-sectional or one-shot, because the data is collected in a single shot from the employees of the telecommunication sector of Pakistan. The population parameter for this study is the telecom sector of Pakistan. According to the PTA's annual report (2019), there are total 4 functional organizations working in the telecom sector of the country which include Jazz, Ufone, Zong, and Telenor[11]. since it is not possible to collect the data from the total population, therefore, a sample has been designed which rightly represents the population parameter of this study. Hence, a sample of 120 respondents was designed to collect the data. This includes 30 respondents from each 4 telecom organizations in Pakistan. 110 responses returned full feedback which was considered as the response rate of $91.66 \%$ which is a satisfactory value [23].

The sampling technique for collecting the data in this case study is a systematic random sampling technique which is one of the types of probability sampling techniques [24]. The subject data of the sample is generalized, and the data was taken from every fourth employee of each company (Zong, Mobilink, Telenor, and Ufone) as also mentioned in the population parameter [24].

According to [23], when the population is complex or hard to be calculated, there is a minimum and maximum range of the sample size which is in the range of 30-500 [23]. Hence, 120 is considered as the most sufficient and significant sample size for this particular study. 30 respondents were considered from each organization of the telecommunication sector of Pakistan.

The instruments and the scalewere were adopted from the previous studies. There was a total of 10 items adopted to measure the overall scale of the gamified recruitment which is the independent variable of this study. Gamified recruitment was composed of three sub-dimensions including persuasive value (4 items), economic value (3 items), and informative value (3 items) [25][26]. The scale was modified a bit following the requirement of this particular study. Similarly, the dependent variables of the study, the team effectiveness having 7 items, is also adopted which is also composed of its three dimensions includes virtual team (3 items), the physical team (2 items), and project team (2 items)[27]. The data was collected using a selfexplanatory questionnaire designed via Google forms. The data was later converted into a spreadsheet which was later exported to SPSS software after some processing. The statistical software SPSS was used to test the hypothesis of the study. Four tests were applied including Cronbach's Alpha (to test the reliability of 


\begin{tabular}{|c|c|c|c|}
\hline Variable & Dimension & $\begin{array}{c}\text { Cronbach's } \\
\text { Alpha }\end{array}$ & \#Items \\
\hline \multirow{2}{*}{$\begin{array}{c}\text { Gamified } \\
\text { Recruitment }\end{array}$} & Persuasive & .935 & 3 \\
\cline { 2 - 4 } & Economic & .932 & 3 \\
\cline { 2 - 4 } & Informative & .929 & 4 \\
\hline \multirow{2}{*}{$\begin{array}{c}\text { Team } \\
\text { Effectiveness }\end{array}$} & Virtual & .942 & 3 \\
\cline { 2 - 4 } & Physical & .944 & 2 \\
\cline { 2 - 4 } & Project & .940 & 2 \\
\hline Total & - & .939 & 17 \\
\hline
\end{tabular}

TABLE 1: Reliability statistics

the scale), descriptive statistics, bivariate correlation test, and linear regression analysis test using SPSS [23].

\section{Results \& Discussion}

The reliability of the scale of this study is measured by Cronbach's Alpha test by processing the data into SPSS (25th version). The general criterion for reliability acceptance (as per Cronbach's Alpha results) is needed to be $0.5(50 \%)$ or more if the number of items is less than or and equal to 10. Moreover, the scale having items greater and equal to 20 would require to have at least $0.7(70 \%)$ or higher value [22][23].

Table 1 shows the results of the reliability test. It shows that items are highly reliable and overall scale has the reliability score of $93.9 \%$ which is strongly accepted to be considered to collect the responses. The reliability score of the scale of physical teams is the highest (94.4\%). Whereas, the informative value part of the gamified recruitment which is based on 4 items has the least Cronbach's Alpha value which is $92.9 \%$. The score is highly acceptable and reliable to be considered for the study.

Since there are no general acceptance criteria for the demographics, therefore, an equal opportunity was given to the participants as it can be seen out of 110 participants. 56 participants are male and 54 participants of the study are females. Meanwhile, most of the participants are from the age group of 26 to 40 years of age. This age group is mature enough to make their own decisions and is most active age group in the workplace. Furthermore, $49.1 \%$ of the samples of the study have a minimum educational qualification of at least Masters or 16 years of education. Therefore, the demographics of the study concludes that the participants are diverse, completely mature who can make their own decision, and are well qualified.

To measure the relationship between the variables, a bivariate correlation test has been applied. The general criteria of the test are to have a significant value of alpha which is less than 0.05 and the relationship between the variables must be considerable (it is acceptable to have more than 15 or 20) [22]. The results of the test are being displayed in Table 3.

According to the test results of bivariate correlation analysis as per Table 3, it can be seen that both the variables, i.e., gamified recruitment and team effectiveness along with their dimensions have significant alpha values, i.e., less than 0.05 and they are highly correlated to each other. It can be seen in Table 3 that gamified recruitment and team effectiveness are correlated with $92.3 \%$ t, alpha $=0.000$. This suggests that variables are highly correlated to one another in telecom sector of Pakistan.

Table 4 shows the results of the linear regression analysis of Model 1. our models have been processed. It is because 4 dependent variables are undertaken in this study which include team effectiveness and three are dimensions of team effectiveness including physical teams, virtual teams, and project teams.

Model 1, as shown in Table 4, shows that model fitness is highly appreciated which is 0.850 at alpha $=0.000$, beta is $92.3 \%$. Thus, the empirical evidence accepts the hypothesis 1 of the study which claims that there is a positive impact of the gamified recruitment on team effectiveness at the telecom sector of Pakistan. In model 2, the persuasive, economic, and informative value of gamified recruitment has been tested on virtual teams' dimension of team effectiveness of the telecom sector of Pakistan. The model fitness is $73 \%$ (Adjusted R Square $=0.730$ ) and the values are significant to support and accept the hypothesis 2 of this study.

In model 3 , given in Table 6 , the fitness is $65.1 \%$ (Adjusted R Square $=0.651$ ) and the values are significant to support and accept the hypothesis 3 of this study. In model 4, given in Table 7, the model fitness is $58.3 \%$ (Adjusted $\mathrm{R}$ Square $=0.583$ ) and the values are significant to support and accept the hypothesis 4 of this study.

\section{Conclusion \& Recommendations}

This study has been performed to evaluate the impact of gamified recruitment on team effectiveness in the telecom sector of Pakistan. The sample of 120 respondents was designed to collect the data. This includes 30 respondents each from 4 telecom sector organizations of Pakistan. 110 responses provided complete feedback which was considered gave the response rate of $91.66 \%$. Both theoretical and empirical evidence has suggested that there is a significant and positive impact of gamified recruitment on team effectiveness. The subdimensions of both gamified recruitment and team effectiveness have also been tested. The empirical ev- 


\begin{tabular}{|c|c|c|c|c|c|}
\hline & & Frequency & Percent & Valid Percent & Cumulative Percent \\
\hline \multirow{4}{*}{ Age (years) } & $20-25$ & 18 & 16.4 & 16.4 & 16.4 \\
\cline { 2 - 6 } & $26-32$ & 42 & 38.2 & 38.2 & 54.5 \\
\cline { 2 - 6 } & $33-40$ & 42 & 38.2 & 38.2 & 10.7 \\
\cline { 2 - 6 } & $41 \&$ above & 08 & 7.3 & 7.3 & 50.9 \\
\cline { 2 - 6 } Gender & Total & 110 & 100.0 & 100.0 & 100.0 \\
\hline & Male & 56 & 50.9 & 50.9 & 36.4 \\
\cline { 2 - 6 } & Female & 54 & 49.1 & 49.1 & 85.5 \\
\cline { 2 - 6 } Education & Total & 110 & 100.0 & 100.0 & 100.0 \\
\cline { 2 - 6 } & Bachelors & 40 & 36.4 & 36.4 & \\
\cline { 2 - 6 } & Masters & 54 & 49.1 & 49.1 & 14.5 \\
\cline { 2 - 6 } & MS/Ph.D. & 16 & 14.5 & 100.0 & \\
\hline
\end{tabular}

TABLE 2: Demographics

\begin{tabular}{|c|c|c|c|c|c|c|c|c|c|}
\hline & & PV & EV & IV & VT & PhT & PT & GR & TE \\
\hline \multirow{3}{*}{ Persuasive Value } & Pearson Correlation & 1 & $.604^{* *}$ & $.704^{* *}$ & $.748^{* *}$ & $.585^{* *}$ & $.636^{* *}$ & $.864^{* *}$ & $.759^{* *}$ \\
\hline & Sig. (2-tailed) & & .000 & .000 & .000 & .000 & .000 & .000 & .000 \\
\hline & $\mathrm{N}$ & 110 & 109 & 109 & 109 & 110 & 110 & 109 & 109 \\
\hline \multirow{3}{*}{ Economic Value } & Pearson Correlation & $.604^{* *}$ & 1 & $.712^{* *}$ & $.718^{* *}$ & $.724^{* *}$ & $.683^{* *}$ & $.854^{* *}$ & $.806^{* *}$ \\
\hline & Sig. (2-tailed) & .000 & & .000 & .000 & .000 & .000 & .000 & .000 \\
\hline & $\mathrm{N}$ & 109 & 109 & 109 & 109 & 109 & 109 & 109 & 109 \\
\hline \multirow{3}{*}{ Informative Value } & Pearson Correlation & $.704^{* *}$ & $.712^{* *}$ & 1 & $.805^{* *}$ & $.775^{* *}$ & $.719^{* *}$ & $.932^{* *}$ & $.876^{* *}$ \\
\hline & Sig. (2-tailed) & .000 & .000 & & .000 & .000 & .000 & .000 & .000 \\
\hline & $\mathrm{N}$ & 109 & 109 & 109 & 109 & 109 & 109 & 109 & 109 \\
\hline \multirow{3}{*}{ Virtual Team } & Pearson Correlation & $.748^{* *}$ & $.718^{* *}$ & $.805^{* *}$ & 1 & $.662^{* *}$ & $.686^{* *}$ & $.858^{* *}$ & $.919^{* *}$ \\
\hline & Sig. (2-tailed) & .000 & .000 & .000 & & .000 & .000 & .000 & .000 \\
\hline & $\mathrm{N}$ & 109 & 109 & 109 & 109 & 109 & 109 & 109 & 109 \\
\hline \multirow{3}{*}{ Physical Team } & Pearson Correlation & $.585^{* *}$ & $.724^{* *}$ & $.775^{* *}$ & $.662^{* *}$ & 1 & $.602^{* *}$ & $.791^{* *}$ & $.845^{* *}$ \\
\hline & Sig. (2-tailed) & .000 & .000 & .000 & .000 & & .000 & .000 & .000 \\
\hline & $\mathrm{N}$ & 110 & 109 & 109 & 109 & 110 & 110 & 109 & 109 \\
\hline \multirow{3}{*}{ Project Team } & Pearson Correlation & $.636^{* *}$ & $.683^{* *}$ & $.719^{* *}$ & $.686^{* *}$ & $.602^{* *}$ & 1 & $.769^{* *}$ & $.860^{* *}$ \\
\hline & Sig. (2-tailed) & .000 & .000 & .000 & .000 & .000 & & .000 & .000 \\
\hline & $\mathrm{N}$ & 110 & 109 & 109 & 109 & 110 & 110 & 109 & 109 \\
\hline \multirow{3}{*}{ Gamified Recruitment } & Pearson Correlation & $.864^{* *}$ & $.854^{* *}$ & $.932^{* *}$ & $.858^{* *}$ & $.791^{* *}$ & $.769^{* *}$ & 1 & $.923^{* *}$ \\
\hline & Sig. (2-tailed) & .000 & .000 & .000 & .000 & .000 & .000 & & .000 \\
\hline & $\mathrm{N}$ & 109 & 109 & 109 & 109 & 109 & 109 & 109 & 109 \\
\hline \multirow{3}{*}{ Team Effectiveness } & Pearson Correlation & $.759^{* *}$ & $.806^{* *}$ & $.876^{* *}$ & $.919^{* *}$ & $.845^{* *}$ & $.860^{* *}$ & $.923^{* *}$ & 1 \\
\hline & Sig. (2-tailed) & .000 & .000 & .000 & .000 & .000 & .000 & .000 & \\
\hline & $\mathrm{N}$ & 109 & 109 & 109 & 109 & 109 & 109 & 109 & 109 \\
\hline
\end{tabular}

TABLE 3: Bivariate correlations analysis

\begin{tabular}{|c|c|c|c|c|c|c|}
\hline \multicolumn{7}{|c|}{ Adjusted R Square $=0.850$} \\
\hline \multirow{2}{*}{\multicolumn{2}{|c|}{ Model }} & \multicolumn{2}{|c|}{ Unstandardized Coefficients } & \multirow{2}{*}{$\frac{\text { Standardized Coefficients }}{\text { Beta }}$} & \multirow{2}{*}{$\mathbf{T}$} & \multirow{2}{*}{ Sig. } \\
\hline & & B & Std. Error & & & \\
\hline \multirow{2}{*}{1} & (Constant) & .568 & 1.174 & & .484 & .629 \\
\hline & Gamified Recruitment & .681 & .027 & .923 & 24.749 & .000 \\
\hline
\end{tabular}

TABLE 4: Linear regression analysis (Model 1)

\begin{tabular}{|c|c|c|c|c|c|c|}
\hline \multicolumn{7}{|c|}{ Adjusted R Square $=0.730$} \\
\hline \multirow{2}{*}{\multicolumn{2}{|c|}{ Model }} & \multicolumn{2}{|c|}{ Unstandardized Coefficients } & \multirow{2}{*}{$\begin{array}{c}\text { Standardized Coefficients } \\
\text { Beta }\end{array}$} & \multirow{2}{*}{$\mathbf{T}$} & \multirow{2}{*}{ Sig. } \\
\hline & & B & Std. Error & & & \\
\hline \multirow{4}{*}{1} & (Constant) & .040 & .757 & & .053 & .958 \\
\hline & Persuasive Value & .312 & .072 & .312 & 4.340 & .000 \\
\hline & Economic Value & .251 & .080 & .227 & 3.124 & .002 \\
\hline & Informative Value & .319 & .061 & .424 & 5.190 & .000 \\
\hline
\end{tabular}

TABLE 5: Linear regression analysis (Model 2) 


\begin{tabular}{|c|c|c|c|c|c|c|}
\hline \multicolumn{7}{|c|}{ Adjusted R Square $=0.651$} \\
\hline \multirow{2}{*}{\multicolumn{2}{|c|}{ Model }} & \multicolumn{2}{|c|}{ Unstandardized Coefficients } & \multirow{2}{*}{$\frac{\text { Standardized Coefficients }}{\text { Beta }}$} & \multirow{2}{*}{$\mathbf{T}$} & \multirow{2}{*}{ Sig. } \\
\hline & & $\mathbf{B}$ & Std. Error & & & \\
\hline \multirow{4}{*}{1} & (Constant) & .334 & .596 & & .559 & .577 \\
\hline & Persuasive Value & .239 & .057 & .314 & 4.165 & .000 \\
\hline & Economic Value & .266 & .063 & .348 & 4.203 & .000 \\
\hline & Informative Value & .270 & .048 & .517 & 5.569 & .000 \\
\hline
\end{tabular}

TABLE 6: Linear regression analysis (Model 3)

\begin{tabular}{|c|c|c|c|c|c|c|}
\hline \multicolumn{7}{|c|}{ Adjusted R Square $=\mathbf{0 . 5 8 3}$} \\
\hline \multirow{2}{*}{\multicolumn{2}{|c|}{ Model }} & \multicolumn{2}{|c|}{ Unstandardized Coefficients } & \multirow{2}{*}{$\begin{array}{c}\text { Standardized Coefficients } \\
\text { Beta }\end{array}$} & \multirow{2}{*}{$\mathbf{T}$} & \multirow{2}{*}{ Sig. } \\
\hline & & B & Std. Error & & & \\
\hline \multirow{4}{*}{1} & (Constant) & .203 & .675 & & .300 & .765 \\
\hline & Persuasive Value & .140 & .064 & .195 & 2.182 & .031 \\
\hline & Economic Value & .243 & .072 & .307 & 3.394 & .001 \\
\hline & Informative Value & .196 & .055 & .363 & 3.577 & .001 \\
\hline
\end{tabular}

TABLE 7: Linear regression analysis (Model 3)

idence has suggested that the persuasive value, economic value, and informative value created by the gamified recruitment have a positive impact on the effectiveness of all three types of teams (physical, virtual, and project) in telecom sector of Pakistan. Therefore, it is highly recommended to the telecom sector of Pakistan to re-evaluate the recruitment process and try to integrate it to the latest gamified recruitment techniques to gain the persuasive, economic, and informative values which will further boost to the team effectiveness in terms to their physical, virtual, and project teams.

\section{Acknowledgement}

This research was conducted at the laboratories of Shah Abdul Latif University (SALU) Khairpur. The authors are grateful to SALU for providing necessary resources to conduct this study.

\section{References}

[1] M.Fetzer, J.McNamara, \& J.L.Geimer, "Gamification, serious games and personnel selection", In H. W. Goldstein, E. D. Pulakos, J. Passmore, \& C. Semedo (Eds.), In: The wiley blackwell handbook of the psychology of recruitment, selection and employee retention, s.l.:John Wiley \& Sons, pp. 293-309, 2017.

[2] I.Nikolaou, K.Georgiou, \& V.Kotsasarlidou, "Exploring the relationship of a gamified assessment with performance", The Spanish Journal of Psychology, pp. 22, 2019.

[3] S.Fitriani, "Teamwork training intervention design to improve team effectiveness to franchise division in company X", International Journal of Research Publication, Vol. 44, No. 1, 2020.
[4] J.Chapman, \& P.Rich,. "Identifying motivational styles in educational gamification", In T. X. Bui, \& R. H. Sprague (Eds.), AIS electronic library 2017. Proceedings of the 50th Hawaii international conference on system sciences, pp. 1318-1327. USA, s.n, 2017.

[5] P.Gkorezis, K.Georgiou, I.Nikolaou, \& A.Kyriazati, "Gamified or traditional situational judgement test? A moderated mediation model of recommendation intentions via organizational attractiveness", European Journal of Work and Organizational Psychology, 2020.

[6] S.Chow, \& D.Chapman, "Gamifying the employee recruitment process", [Paper presentation], Proceedings of the First International Conference on Gameful Design, Research, and Applications. Toronto, Ontario, and Canada., s.n, 2013.

[7] J.Koivisto, \& J.Hamari, "The rise of motivational information systems: A review of gamification research", International Journal of Information Management, Vol. 45, pp. 191-210, 2019.

[8] M.Cardador, G.Northcraft, \& J.Whicker, "A theory of work gamification: Something old, something new, something borrowed, something cool?", Human Resource Management Review, pp. 27, 353-365, 2017

[9] S.Deterding, "Gamification. using game-design elements in non-gaming contexts", In CHI'11 extended abstracts on human factors in computing systems, pp. 2425-2428, New York: Association for Computing Machinery, 2011.

[10] S.A.Woods, "Personnel selection in the digital age: A review of validity and applicant reactions, and future research challenges", European Journal of Work and Organizational Psychology, Vol. 29, No. 1, pp. 64-77, 2020.

[11] P.T.Authority, "Annual Report", PTA Headquarters, F5/1, Islamabad — www.pta.gov.pk: Pakistan Telecommunication Authority (PTA), 2019.

[12] D.Song, "Engaged cohorts: Can gamification engage all college students in class?", Eurasia Journal of Mathematics, Science \& Technology Education, Vol. 13, pp. 3723-3734, 2017.

[13] I.Nikolaou, T.N.Bauer, \& D.M.Truxillo, "Applicant reactions to selection methods: An overview of recent research and suggestions for the future", In I.Nikolaou \& J.K.Oostrom (Eds.), Employee recruitment, pp. 80-96, 
Routledge. 2015.

[14] M.Sakamoto, T.Nakajima, \& T.Alexandrova, "Valuebased design for gamifying daily activities", In M. Herrlich, R. Malaka, \& M. Masuch (Eds.), Springer-Verlag Berlin 2012, Proceedings of the 11th international conference on entertainment computing, pp. 421-424, Heidelberg, Berlin, Springer Verlag, 2012.

[15] K.Seaborn, \& D.Fels, "Gamification in theory and action: A survey", International Journal of Human-Computer Studies, Vol. 74, pp. 14-31, 2015.

[16] D.Mcewan, "The effectifeness of teamwork training on teamwork behavior and teamperfomance", A systematic review and Meta-Analysis of controlled Interversion, 2017.

[17] L.Hakulinen, T.Auvinen, \& A.Korhonen, "Empirical study on the effect of achievement badges in TRAKLA2 online learning environment", In J.E.Guerrero (Ed.), IEEE computer society, Proceedings of the learning and teaching in computing and engineering (LaTiCE), pp. 47-54, 2013.

[18] M.D.Hanus, \& J.Fox, "Assessing the effects of gamification in the classroom: A longitudinal study on intrinsic motivation, social comparison, satisfaction, effort, and academic performance", Computers \& Education, Vol. 88, pp. 152-161, 2015.

[19] K.Robson, "Is it all a game? Understanding the principles of gamification", Business Horizons, Vol. 58, pp. 411-420, 2015.

[20] J.R.V.Prasad, J.Alexander, \& S.Misra, "Gamification and Employees' Perception: An Empirical Evaluation Using Gamification Effectiveness scale", Int. J. Manag. Bus. Research, Vol. 9, No. 2, pp. 19-27, 2019.

[21] K.Werbach, \& D.Hunter, "For the Win: How game thinking can revolutionalize your business", Wharton: Digital Press, 2012.

[22] M.Saunders, P.Lewis, \& A.Thornhill, "Understanding research philosophy and approaches to theory development", In: Understanding research philosophies and approaches, pp. 124, 2015.

[23] U.Sekaran, \& R.Bougie, "Research Methods for Business A skill-building approach", 2010.

[24] A.S.Acharya, A.Prakash, \& A.Nigam, "Sampling: Why and How of it?", Indian Journal of Medical Specialities, Vol. 4, No. 2, pp. 330-333, 2013.

[25] Venkatesh, F.D.Davis, \& G.B.Davis, "User Acceptance of Information Technology: Toward a Unified View", MIS Quarterly, Vol. 27, pp. 425-478, 2003.

[26] J.E.Plaks, \& K.Stecher, "Unexpected Improvement, Decline, and Stasis: A Prediction Confidence Perspective on Achievement Success and Failure", Journal of Personality and Social Psychology, Vol. 93, pp. 667-684, 2007

[27] O.Hongseok, M.H.Chung, \& Giuseppe, "Labianca Group Social Capital and Group Effectiveness: The Role of Informal Socializing Ties", Academy of Management Journal, Vol. 47, pp. 860-875, 2004. 